\title{
CLARICE LISPECTOR: APRENDIZAGENS E PRAZERES DA CRÔNICA
}

Clarice Lispector: learning and pleasures of the chronicle

\author{
Marcos Vinicius Scheffel \\ https://orcid.org/0000-0002-6418-8327 0 \\ Universidade Federal do Rio de Janeiro, Faculdade de Educação, Rio de Janeiro, RJ, Brasil. \\ 22290-255 - direcaofeufrj@gmail.com
}

LISPECTOR, Clarice. Todas as crônicas Clarice Lispector. Prefácio de Marina Colasanti; organização e posfácio de Pedro Karp Vasques; pesquisa textual de Larissa Vaz. Rio de Janeiro: Rocco, 2018.

É célebre a frase do narrador de Água viva, de Clarice Lispector, ao refletir sobre a fluidez de sua escrita: "gênero não me pega mais" (LISPECTOR, 2019, p. 30). É tentador para muitos que estudam a obra da autora pensar desta forma e se ater apenas às virtualidades da escrita clariceana e deixar de lado classificações como conto, crônica, novela ou romance. Ao se dedicar à escrita de crônicas - atividade que teve início em 1946 e se estendeu até 1977, ano de sua morte - a autora em vários momentos teve que refletir sobre o gênero. Isto se dá principalmente a partir de sua contribuição para o Jornal do Brasil - onde ocupou um lugar de destaque entre 19 de agosto de 1967 e 29 de dezembro de 1973 - com uma contribuição semanal aos sábados: "Crônica é um relato? É uma conversa? é o resumo de um estado de espírito? Não sei, pois antes de começar a escrever para o Jornal do Brasil, eu só tinha escrito romances e contos." (LISPECTOR, 2018, p. 118119)

A necessidade de refletir sobre a crônica pode ser pensada por vários vieses: tratavase de uma escrita remunerada, semanal e de um gênero que gozava de grande prestígio entre o público leitor. Nesse sentido, Clarice constata que os cronistas do Rio de Janeiro são amados por seus leitores e sente o peso da responsabilidade de escrever num período em que havia autores como Rubem Braga, Armando Nogueira, Carlos Drummond de Andrade, Elsie Lessa, Rachel de Queiroz e Dinah Silveira de Queiroz se dedicando ao gênero. São os cronistas que lançam um olhar diferenciado sobre o cotidiano da cidade, mas, ao fazerem isso, passam a ser objeto de atenção dos seus leitores, que lhes enviam cartas, sugerem temas, comentam a crônica da semana anterior. Este fato de ser observada gera inclusive uma situação tensa, quando descobre que um dos seus vizinhos 
a observava de binóculo.

Mas um dos principais aprendizados sobre a crônica é que era impossível escrevêlas sem colocar muito de si, sem falar de si, sem colocar seu ponto de vista sobre os fatos do cotidiano. Essa descoberta acaba por gerar uma angústia na escritora que se sentia protegida no romance e no conto:

Na literatura de livros permaneço anônima e discreta. Nesta coluna estou de algum modo me dando a conhecer. Perco minha intimidade secreta? Mas o que fazer? É que escrevo ao correr da máquina e, quando vejo, revelei certa parte minha. Acho que se escrever sobre o problema da superprodução do café no Brasil terminarei sendo pessoal. Daqui em breve serei popular? Isto me assusta. (LISPECTOR, 2018, p. 147).

Rubem Braga, com quem Clarice manteve intenso diálogo neste período e que ela considerava o "inventor da crônica" (LISPECTOR, 2018, p. 90), tranquiliza-a e afirma que se tratava de um caminho sem volta para o cronista, que deve realmente fornecer um ponto de vista subjetivo sobre o cotidiano. Deve-se observar que Clarice Lispector pouco se vale de uma outra característica do gênero - bastante explorada por Carlos Drummond de Andrade - escrever as crônicas a partir do jornal e suas várias seções (as pequenas e as grandes notícias, os anúncios, o horóscopo).

Ao ler o conjunto das crônicas de Clarice Lispector, agora reunidas no volume Todas as crônicas, editora Rocco (2018, 70 páginas), prefácio de Marina Colasanti, organização e posfácio Pedro Karp Vasquez e pesquisa textual de Larissa Vaz, pode-se constatar que apesar do incômodo de ter que "dar-se a conhecer", registrado em várias crônicas, é este o caminho seguido pela autora e que crônicas dialogando com o jornal e suas várias seções são raras. Nota-se ainda que mesmo entre estas crônicas, surgidas do jornal, há um interesse da autora sobre o que falam dela nos jornais. Um exemplo disto é o diálogo que trava com o cronista esportivo Armando Nogueira que desafiava Clarice Lispector a escrever sobre futebol. A autora faz um longo rodeio, elogia o estilo do renomado cronista esportivo, confessa sua paixão pelo Botafogo, mas provoca-o e desafia-o a "escrever sobre a vida" (LISPECTOR, 2018, p.70).

Perceber que Clarice Lispector pouco se vale do diálogo com o jornal e acaba por produzir uma crônica mais pessoal, mais existencial, que mesmo assim parecia gozar de grande prestígio entre os leitores pelo número de cartas que recebia (informação dada pela autora), acaba por revelar alguns dos problemas da presente edição: 1) a ausência de uma das crônicas mais famosas de Clarice Lispector, "Mineirinho"; 2) o uso do título do livro Para não esquecer - na última seção deste livro.

Quanto à "Mineirinho", deve-se lembrar que o texto figurou num primeiro momento no livro A legião estrangeira de 1964 que tinha em sua capa a seguinte informação: contos e crônicas. Sendo que "Mineirinho" estava na segunda parte do livro chamada de "Fundo de Gaveta", ou seja, foi considerado pela própria autora como crônica. Sabe-se ainda que "Mineirinho" fora publicada pela primeira vez na Revista Senhor em 1962 e se originou de uma notícia de ampla repercussão jornalística: o assassinato pela polícia de José Miranda 
Rosa, vulgo Mineirinho, em $1^{\circ}$ de maio de 1962. Fora estes aspectos ligados ao suporte, "Mineirinho" traz características prototípicas do gênero, a saber: diálogo com o leitor, o ponto de vista extremamente subjetivo sobre um fato do cotidiano, a tomada de uma posição sobre um tema que podia dividir opiniões e por isto de interesse dos leitores do jornal / revista (a morte de um contraventor) - neste último ponto a crônica apresenta um forte caráter argumentativo. Quanto a Clarice Lispector, ela não publicou "Mineirinho" como conto em nenhuma das novas organizações que deu em vida para seus livros de contos. Depois de sua morte, em 1977, "Mineirinho" foi sistematicamente publicada em Para não esquecer ${ }^{1}$, coletânea de crônicas, por várias editoras.

Causa estranheza que este título Para não esquecer seja (re)utilizado pela editora para dar nome a uma das seções do livro que traz 15 crônicas (12 delas que constam das edições anteriores do livro e 3 incluídas nesta organização) e que o destino das outras 96 crônicas do livro não seja bem explicado. Ao que tudo indica, elas foram reorganizadas por data e veículo de divulgação no restante do livro. Outras tinham sido incluídas em 2016 no volume Todos os contos, organizado por Benjamin Moser. Deve-se lembrar que este volume saiu primeiro nos Estados Unidos em 2015, tendo sido aclamado como um dos melhores livros do ano pelo jornal The New York Times. Este objetivo de divulgar a obra de Clarice Lispector para leitores não familiarizados com a autora levou Moser a incluir na antologia "Mineirinho" que é nas suas palavras "stricto sensu, jornalístico, mas o seu estilo se aproxima mais dos contos." (MOSER, 2016, p. 378). Trata-se de um critério editorial explicável para uma edição norte-americana já que as especificidades da crônica brasileira, algumas delas citadas aqui, necessitariam de um verdadeiro estudo literário, que explicasse, por exemplo, os motivos de Clarice Lispector chamar Rubem Braga de "criador da crônica" quando se trata de um gênero praticado desde o século XIX no país e com grande prestígio. O que Clarice queria dizer com isto - fora o elogio ao amigo?

Já na edição de Todas as crônicas a explicação da exclusão de crônicas como "Mineirinho" se limita a um aspecto editorial: o texto já foi previamente publicado em Todos os contos. Nas palavras do organizador Pedro Karp Vaz: "De modo geral, eram crônicas que eram reaproveitadas como contos. Contudo, conforme demonstrado nos dois casos citados, o contrário também acontecia: contos eram publicados na imprensa como crônicas." (KARP, 2018, p. 512) Esta explicação parece desconsiderar o próprio material publicado, pois um dos temas citados com frequência por Clarice Lispector é a dificuldade de manter a regularidade de publicar semanalmente sua crônica, de escrever contra o relógio:

Sinto que já cheguei à liberdade. A ponto de não precisar escrever. Se eu pudesse, deixava meu lugar nesta página em branco: cheio do maior silêncio. E cada um que olhasse o espaço em branco, o encheria com seus próprios desejos.

Vamos falar a verdade: isto aqui não é uma crônica coisa nenhuma. Isto é

\footnotetext{
${ }^{1}$ Não há registros de quem organizou este livro que tem sua primeira edição pela Ática e Ediouro (1978) e depois edições pela Círculo do Livro (1980), Sciliano (1992) e Rocco (1999).
} 
apenas. Não entra em gênero. Gêneros não me interessam mais. Interessame o mistério. (LISPECTOR, 2018, p. 404)

Logo após esta breve abertura, a cronista faz uma extensa lista das verdades que a espantam, deixando transparecer que esta fora a estratégia usada para preencher o branco da página, a falta de assunto. Para preencher este "espaço em branco" Clarice se vale de outras estratégias como: "requentar" / "reutilizar" textos já publicados (caso dos contos colocados no espaço reservado à crônica); construir a crônica com recortes do cotidiano / aforismos e impressões subjetivas; falar de conversas que tivera com amigos ou com taxistas; citar cartas de leitores - podendo chegar à extrema liberdade de publicar na íntegra uma belíssima carta que Fernanda Montenegro Ihe enviara. Naquele espaço a carta deixa de ser carta e vira crônica de Clarice Lispector. Um verdadeiro ready-made.

Quanto à edição, a reunião destes textos por veículos de publicação (Jornal do Brasil, Senhor, O Jornal, Última Hora) e em ordem cronológica², permite, entre outras coisas, que se tenha uma percepção de como Clarice Lispector lidou com a obrigação de escrever semanalmente e das estratégias que usou para "preencher" este espaço do jornal.

Também é louvável o fato de a edição trazer 120 crônicas inéditas da autora para o grande o público, apesar de não estarem claros os critérios desta pesquisa, que foi assim explicada pelo organizador em entrevista ao site Metrópoles: "Larissa [responsável pela pesquisa textual] foi obrigada a fotografar com o celular os textos que encontrou, pois a grande maioria nunca havia sido microfilmada, reproduzida fotograficamente ou escaneada. Com esse material em mãos, efetuamos um cruzamento para evitar eventuais repetições." (FLÁVIO, 2018, n.p). Ficam muitas dúvidas aqui: quais critérios utilizados para pesquisa? qual a familiaridade dos pesquisadores com arquivos e pesquisas do gênero? outros arquivos foram considerados? ${ }^{3}$

Seria útil um trabalho futuro com um perfil mais acadêmico, sem as limitações de uma edição estritamente comercial, com um bom texto explicando a pesquisa nos arquivos, com algumas notas pontuais, com um contexto da crônica brasileira nos anos 1960 e 70 para os leitores contemporâneos que não imaginam o prestígio do gênero naquele período e com critérios mais objetivos, que denotem pesquisa cuidadosa sobre a autora e sua atuação na imprensa, para se incluir ou excluir uma crônica do volume. Tudo isto, que já foi feito com outros cronistas brasileiros, poderia dimensionar melhor o trabalho de Clarice Lispector como cronista, que é de extrema qualidade e de domínio do gênero.

\footnotetext{
2 Há uma opção editorial de primeiro publicar as crônicas que saíram no Jornal do Brasil, em maior número, e depois as publicações em menor número nos demais veículos. Esta escolha editorial é explicada no posfácio.

${ }^{3}$ Não há informações no livro sobre os dois organizadores / pesquisadores.
} 


\section{Referências}

FLÁVIO, Lúcio. Livro reúne mais de 100 crônicas inéditas de Clarice Lispector. Metrópoles, 29 set. 2018. Disponível em: https://www.metropoles.com/entretenimento/literatura/livroreune-mais-de-100-cronicas-ineditas-de-clarice-lispector. Acesso em: 20 fev. 2019.

LISPECTOR, Clarice. Todas as crônicas Clarice Lispector. Prefácio de Marina Colasanti; organização e posfácio de Pedro Karp Vasques; pesquisa textual de Larissa Vaz. Rio de Janeiro: Rocco, 2018.

LISPECTOR, Clarice. Todos os contos Clarice Lispector. Prefácio e organização de Benjamin Moser. Rio de Janeiro: Rocco, 2016.

LISPECTOR, Clarice. Água viva. Rio de Janeiro: Rocco, 2019.

KARP, Pedro. Posfácio. In: LISPECTOR, Clarice. Todas as crônicas Clarice Lispector. Prefácio de Marina Colasanti; organização e posfácio de Pedro Karp Vasques; pesquisa textual Larissa Vaz. Rio de Janeiro: Rocco, 2018, p. 510-521.

MOSER, Benjamin. Apêndice. In: LISPECTOR, Clarice. Todos os contos Clarice Lispector. Prefácio e organização de Benjamin Moser. Rio de Janeiro: Rocco, 2016, p. 374-377.

\section{NOTAS DE AUTORIA}

Marcos Vinícius Scheffel (marcos.scheffel53@gmail.com) é licenciado em Letras pela Universidade da Região de Joinville (2001). Mestre em Literatura Brasileira (UFSC, 2007) e Doutor em Teoria da Literatura (UFSC, 2011) - ambos com pesquisas sobre Lima Barreto. Professor da Universidade Federal do Amazonas entre 2008 e 2013. Professor da Faculdade de Educação da UFRJ desde 2013. Professor do Mestrado Profissionalizante em Letras - ProfLetras / UFRJ. Realiza estágio de pós-doutorado na Universidade Federal de Pernambuco.

\section{Como citar esse artigo de acordo com as normas da ABNT}

SCHEFFEL, Marcos Vinícius. Clarice Lispector: aprendizagens e prazeres da crônica. Anuário de Literatura, Florianópolis, v. 26, p. 01-06, 2021.

\section{Contribuição de autoria}

Não se aplica.

\section{Financiamento}

Não se aplica.

\section{Consentimento de uso de imagem}

Não se aplica.

\section{Aprovação de comitê de ética em pesquisa}

Não se aplica.

\section{Conflito de interesses}

Não se aplica.

\section{Licença de uso}

Os/as autores/as cedem à Revista Anuário de Literatura os direitos exclusivos de primeira publicação, com o trabalho simultaneamente licenciado sob a Licença Creative Commons Attribution (CC BY) 4.0 International. Estra licença permite que terceiros remixem, adaptem e criem a partir do trabalho publicado, atribuindo 0 devido crédito de autoria e publicação inicial neste periódico. Os autores têm autorização para assumir contratos adicionais separadamente, para distribuição não exclusiva da versão do trabalho publicada neste 
periódico (ex.: publicar em repositório institucional, em site pessoal, publicar uma tradução, ou como capítulo de livro), com reconhecimento de autoria e publicação inicial neste periódico.

\section{Publisher}

Universidade Federal de Santa Catarina. Programa de Pós-graduação em Literatura. Publicação no Portal de Periódicos UFSC. As ideias expressadas neste artigo são de responsabilidade de seus/suas autores/as, não representando, necessariamente, a opinião dos/as editores/as ou da universidade.

\section{Histórico}

Recebido em: 24/08/2020

Aprovado em: 28/09/2020

Publicado em: 23/04/2021 